\title{
MuSK controls where motor axons grow and form synapses
}

\author{
Natalie Kim and Steven J. Burden \\ Molecular Neurobiology Program, The Helen L. and Martin S. Kimmel Center for Biology and \\ Medicine at the Skirball Institute of Biomolecular Medicine, NYU Medical School, 540 First \\ Avenue, N.Y., NY 10016
}

\section{Summary}

It had long been thought that motor axons approach muscles that are regionally unspecialized and induce postsynaptic differentiation by releasing signals that focally initiate transcriptional and post-translational responses in muscle. This neuro-centric view of synapse formation, however, has been challenged by recent experiments, which showed that AChR clusters are concentrated in the central region of muscle independent of innervation. This nerve-independent prepattern of $\mathrm{AChR}$ expression requires MuSK, a receptor tyrosine kinase that is critical for synapse formation. How muscle prepatterning is established and whether motor axons recognize this prepattern are not known. Here, we show that $M u S K$ itself is prepatterned in muscle and that high, ectopic $M u S K$ expression is sufficient to promote ectopic motor axon growth and synapse formation, indicating that the muscle prepattern is recognized by motor axons and promotes synapse formation in the central region of developing mammalian muscle. Further, we provide evidence that early expression of $M u S K$ in developing myotubes is sufficient to re-establish muscle prepatterning independent of the $M u S K$ promoter. Moreover, we show that ectopic MuSK expression stimulates synapse formation in the absence of Agrin and rescues the neonatal lethality of agrin mutant mice, demonstrating that MuSK, independent of Agrin, is sufficient to direct presynaptic and postsynaptic differentiation. In contrast to a neuro-centric view for synapse formation, these data demonstrate that the postsynaptic cell can play a dominant role in regulating synapse formation.

\section{Keywords}

synapse formation; muscle prepatterning; agrin; receptor tyrosine kinase

\section{Introduction}

Once axons project to their target area, they branch within their target field in a highly stereotyped manner. This organizational feature of neurons is critical to form synapses on appropriate target cells and to establish functional neuronal circuits. The mechanisms that direct and confine axon branching and synapse formation to a defined target area, however, are poorly understood. In mammals, neuromuscular synapses are located within a narrow endplate band in the central region of the muscle, marked by presynaptic nerve terminals, postsynaptic clusters of acetylcholine receptors (AChRs) and elevated levels of $A C h R$ gene expression (for reviews see (Burden, 1998; Sanes and Lichtman, 1999, 2001). A cardinal question in vertebrate synapse formation is how this characteristic and stereotyped pattern of innervation is established and which roles nerve and muscle play in shaping this topographic arrangement.

\footnotetext{
*Corresponding author: Steven J. Burden, TEL: (212) 263 7341, FAX: (212) 263 8214, burden@ saturn.med.nyu.edu. The authors do not have a conflict of interest related to this work.
} 
It had long been thought that motor axons approach a muscle that is regionally unspecialized and induce postsynaptic differentiation by releasing signals that focally initiate transcriptional and post-translational responses in the muscle (Bennett and Pettigrew, 1974, 1976; Burden, 1998; Kandel et al., 2000; Sanes and Lichtman, 2001; Schaeffer et al., 2001). These studies implicated motor neuron-derived Agrin, a glycosylated proteoglycan, as the critical neural signal for inducing postsynaptic differentiation and the muscle-specific receptor tyrosine kinase, MuSK, a component of the Agrin receptor, as the transducer for clustering AChRs and activating AChR gene expression at synaptic sites (Burden, 1998; Glass et al., 1996a; Glass et al., 1996b; Glass and Yancopoulos, 1997; Sanes and Lichtman, 2001; Schaeffer et al., 2001; Valenzuela et al., 1995). This neuro-centric view of neuromuscular synapse formation, however, has been challenged by recent experiments, which showed that mammalian muscle is spatially patterned independent of innervation. In mice that lack DNA topoisomerase II $\beta$, motor axons fail to innervate diaphragm and limb muscles, yet AChR clusters are concentrated in the central region of these muscles (Yang et al., 2000). Subsequent studies, which examined the roles of Agrin and MuSK in nerveindependent muscle patterning, demonstrated that MuSK, but not Agrin is required to cluster AChRs in the central region of the muscle (Lin et al., 2001; Yang et al., 2001). This nerveindependent prepattern of AChR expression is then modified and sharpened by two neural signals: Agrin, which stabilizes AChR clusters, and acetylcholine (ACh), which extinguishes AChR clusters (Lin et al., 2005; Misgeld et al., 2005). As a consequence, AChR clusters are selectively maintained at nascent synapses and dispersed at non-synaptic sites. These genetic studies in mice have been complemented by live-imaging of neuromuscular synapse formation in zebrafish (Flanagan-Steet et al., 2005; Panzer et al., 2006), which showed that this pattern of $\mathrm{AChR}$ expression is established prior to innervation and suggested that motor axon growth cones grow toward this prepatterned zone (Panzer et al., 2006).

Important aspects of muscle pre-patterning, however, remain poorly understood. The muscle intrinsic mechanisms that are responsible for establishing regional differences in muscle prior to innervation are not known. Further, it is not known whether this pre-existing regional specialization in the muscle is recognized by approaching motor axons and has a role in confining axon branching and synapse formation to the appropriate target field within the muscle.

In this study we show that $M u S K$ itself is expressed preferentially in the central region of muscle independent of innervation and that this spatial pattern of $M u S K$ expression dictates where motor axons grow and where synapses will form. Moreover, surprisingly, ectopic MuSK stimulates the formation of ectopic synapses independent of Agrin, demonstrating that MuSK activation, independent of Agrin, is sufficient to stimulate presynaptic and postsynaptic differentiation. Further, we provide evidence that early expression of MuSK in developing muscle, conferred by the skeletal $\alpha$-actin promoter, is sufficient to initiate muscle prepatterning in mice that lack endogenous $M u S K$ and motor neurons, consistent with the idea that early expression of MuSK, together with the pattern of muscle growth and positive feedback by MuSK, is sufficient to establish muscle prepatterning.

\section{Results}

\section{MuSK expression is patterned in muscle lacking motor axons}

$A C h R$ gene expression and AChR clusters are concentrated in the central region of skeletal muscle in the absence of innervation (Lin et al., 2001; Yang et al., 2001; Yang et al., 2000). This nerve-independent patterning of AChR expression, termed muscle prepatterning, is dependent upon MuSK (Lin et al., 2001; Yang et al., 2001), a receptor tyrosine kinase that is activated by Agrin and essential for neuromuscular synapse formation (DeChiara et al., 1996; Strochlic et al., 2005). To determine whether $M u S K$ itself is prepatterned in muscle 
lacking motor axons, we examined the pattern of $M u S K$ expression in muscles from mice that lack motor axons. Mice that lack motor neurons were generated by crossing $H B 9^{c r e}$ mice, which express Cre recombinase selectively in developing motor neurons, with Isl $2^{\text {loxP-stop-loxP-DTA }}$ mice, which, following Cre-mediated deletion of a translational stop sequence, express diphtheria toxin A (DTA) from the isl2 gene (Yang et al., 2001). In mice carrying both alleles, DTA is expressed in developing motor neurons, leading to death of motor neurons before they differentiate and extend axons into muscle (Yang et al., 2001). We found that $M u S K$ mRNA, like $A C h R$ mRNA, is concentrated in the central region of muscles from $H B 9^{\text {cre }}$; Isl2 loxP-stop-loxP-DTA $\left(I s l 2^{D T A}\right.$ ) mice (Figure 1B, D). Thus, MuSK expression is itself restricted to the central muscle region independent of innervation, suggesting that the pattern of $M u S K$ expression defines the region of $\mathrm{AChR}$ expression in the absence of motor axons.

\section{High, ectopic MuSK expression induces ectopic AChR clusters}

To determine whether this restricted pattern of MuSK expression dictates the pattern of AChR clustering in muscle lacking motor neurons, we generated transgenic mice that express MuSK uniformly throughout the muscle, under the control of the human skeletal $\alpha$ actin (HSA) regulatory region (Figure $1 \mathrm{E}$ ). We analyzed two $H S A: \because M u S K$ transgenic lines, $M u S K-L$ and $M u S K-H$, which overexpress $M u S K$ by 3- and 20-fold, respectively (Figure $1 \mathrm{~F}$, G, H, I).

To determine whether ectopic MuSK expression induces ectopic AChR clusters in muscle lacking motor axons, we generated $H B 9^{c r e}$; Isl $2^{D T A}$ mice that carry either the $M u S K-L$ or $M u S K-H$ transgene, and we stained for AChRs with Alexa-594- $\alpha$-bungarotoxin ( $\alpha$-BGT). We found that uniform expression of MuSK from the high-expressing $M u S K-H$ transgene, but not the low-expressing $M u S K-L$ transgene, is sufficient to induce AChR clusters throughout the muscle of mice lacking motor neurons (Figure 2D, F, G). Thus, high ectopic MuSK expression is sufficient to perturb muscle prepatterning and induce ectopic AChR clustering.

\section{High, ectopic MuSK expression promotes motor axon outgrowth}

We next examined whether disruption of the muscle prepattern perturbed motor axon growth. We stained whole mounts of diaphragm muscles with antibodies to Neurofilament (NF) and Synaptophysin (Syn) to visualize axons and nerve terminals, respectively, and with $\alpha$-BGT to mark postsynaptic AChRs. We found that uniform expression of $M u S K$ from the high-expressing $M u S K-H$ transgene, but not the low-expressing $M u S K-L$ transgene, is sufficient to induce motor axon growth throughout the muscle (Figure 3C, E). Similar exuberant axon growth was found in limb muscles (data not shown). Indeed, quantification of axon growth shows that motor axons in $M u S K-H$ mice extend to cover nearly the entire $(\sim 90 \%)$ muscle (Figures 3G, S1). Thus, high, ectopic MuSK expression, sufficient to alter muscle prepatterning and induce $\mathrm{AChR}$ clustering, is sufficient to promote motor axon growth, suggesting that muscle prepatterning normally restricts motor axons to this prespecialized region of the muscle.

\section{Ectopic MuSK induces ectopic synapses}

Ectopic motor axons in $M u S K-H$ mice terminate and form specializations in peripheral regions of the muscle, which appear identical to synapses in the central region of muscle from wild-type mice (Figure 4A, B, C). In wild-type mice, synapses form a band that occupies the central $\sim 10 \%$ of the muscle, whereas in $M u S K-H$ mice the synaptic zone covers nearly $90 \%$ of the muscle, similar to the distribution of motor axons in these muscles (Figures 4D, S2). 
In mammalian muscle, nearly all muscle fibers bear a single synaptic site (Sanes and Lichtman, 1999). We counted the number of synapses within a defined area of the diaphragm muscle from wild-type and $M u S K-H$ mice and found that the number of synapses is $28.67 \pm 3.7 \%$ greater in muscle from $M u S K-H$ mice (Figures $4 \mathrm{E}, \mathrm{S} 2$ ). We sought to determine the source of these additional synapses and found that diaphragm muscles from wild-type and $M u S K-H$ mice contain a similar number of muscle fibers (Figures 4F, G, S2), indicating that a subset of myofibers, possibly as high as $\sim 30 \%$ of the total, contain more than one synaptic site in MuSK-H mice. We counted the number of Isl1/2-positive motor neurons in the cervical, thoracic and lumbar regions of the spinal cord from wild-type and $M u S K-H$ mice and found that $M u S K-H$ mice contain a normal number of motor neurons (Figures 4H, I, S3), indicating that the additional synapses arise from increased branching of a fixed number of motor neurons rather than from increased motor neuron survival. To determine whether these additional synapses are generated from branches that arise from axons or terminals, we counted the number of terminal sprouts in diaphragm muscles from wild-type and $M u S K-H$ mice. Although we detect a modest level of terminal sprouting in $M u S K-H$ mice (4 terminal sprouts/495 synapses examined in $M u S K-H$ mice and no terminal sprouts/401 synapses in wild-type mice; Figure 4J, K, L), the extent of terminal sprouting cannot account for the increase in the number of synapses. Thus, most of the additional synapses in $M u S K-H$ mice appear to arise from collateral branching of motor axons.

Nascent neuromuscular synapses undergo a complex process of maturation during the first few weeks after birth. One of the more striking changes is the elaboration of a plaqueshaped form at birth to a pretzel-shaped form postnatally (Sanes and Lichtman, 1999; Slater, 1982a, b). This transition occurs normally in $M u S K-H$ mice, since synaptic AChR clusters become perforated and highly branched, like in wild-type mice (Figure 5D, E). In addition to $\mathrm{AChR}$ clusters that are associated with nerve terminals, muscles from $\mathrm{MuSK}-\mathrm{H}$ mice bear numerous ectopic, non-synaptic AChR clusters (Figures 5F, K, L, N, S4), which are maintained postnatally (Figures 5F, S1). Unlike synaptic AChRs, these non-synaptic AChRs do not mature postnatally but instead retain the typical oval plaque-shape of nascent synaptic AChR clusters (Figure 5F). These findings indicate that spatially restricted, nerve-derived signals are required for this aspect of postsynaptic maturation in vivo.

During normal fetal development, individual synaptic sites are innervated by multiple axons, which are gradually eliminated during the first few weeks after birth so that each synaptic site is ultimately innervated by only a single motor axon (Nguyen and Lichtman, 1996). Synaptic sites in MuSK-H mice are likewise multiply innervated during fetal development (Figure 5H), and although the rate of synapse elimination is delayed (Figure 5I), by P30, all synaptic sites in $M u S K-H$ mice are singly innervated (data not shown).

\section{Early MuSK expression is sufficient to initiate muscle prepatterning}

Our data demonstrate that $M u S K$ expression is patterned independent of innervation and that this prepatterning has an important role in regulating where synapses form in muscle. We next sought to determine how MuSK prepatterning is established. Previously, we raised the possibility that the temporal pattern of muscle growth might have an important role in clustering AChRs in the central region of muscle (Yang et al., 2000). Notably, because myoblasts fuse to developing myotubes at their growing ends, the central region of muscle is more mature than the distal ends of the muscle (Williams and Goldspink, 1971; Zhang and McLennan, 1995). Further, MuSK is expressed shortly after myoblasts fuse to form myotubes, and MuSK activation stimulates MuSK protein clustering and MuSK expression (Jones et al., 1999; Lacazette et al., 2003; Moore et al., 2001; Sander et al., 2001). These data raise the possibility that stochastic activation of MuSK in early myotubes, followed by both positive feedback loops, might be sufficient to initiate and sustain MuSK signaling in 
the central region of the muscle, where it is first expressed and activated (Figure 6H) (Arber et al., 2002).

The skeletal muscle alpha-actin and MuSK promoters share similar temporal patterns of expression, as the actin promoter, like the $M u S K$ promoter, is activated in developing myotubes (Brennan and Hardeman, 1993; Minty et al., 1982). However, unlike the MuSK gene, the actin gene is expressed uniformly throughout the myotube (Fontaine et al., 1988). To determine whether early expression of $M u S K$ might be sufficient to pattern AChR clustering in muscle, we crossed the low-expressing $H S A:: M u S K-L$ transgene, which does not perturb AChR pre-patterning (Figure 2F), into mice that lack motor neurons and endogenous MuSK. Despite uniform expression from the actin promoter, we considered the possibility that early expression of MuSK protein, followed by stochastic activation, sustained by the post-translational feedback loop, might be sufficient to concentrate and activate MuSK in the central region of the muscle (Figure 6I).

We generated mice that lack motor neurons and endogenous $M u S K$ but carry the $M u S K-L$

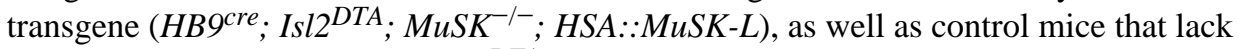

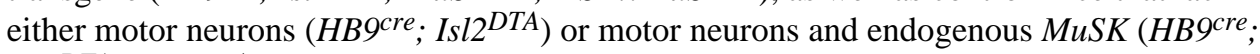
$I s l 2^{D T A} ; \mathrm{MuSK}^{-1-}$ ), and we examined the pattern of AChR clustering in muscle from E13.5 mice. As shown previously, AChR clusters are patterned in the central region of muscle lacking motor neurons but not in mice lacking both motor neurons and MuSK (Lin et al., 2001; Yang et al., 2001) (Figure 6A, D). However, in mice lacking motor neurons and endogenous $M u S K$, but carrying the $M u S K-L$ transgene, AChR clusters are patterned in the central region of muscle (Figure 6C), and the width of this zone is indistinguishable from control mice (Figure 6G). These data demonstrate that the actin promoter can replace the $M u S K$ promoter and re-establish muscle prepatterning. Thus, early but uniform $M u S K$ expression is sufficient to pattern the central region of the muscle. These findings are consistent with the idea that this early MuSK expression leads to stochastic MuSK activation, which is reinforced by feedback mechanisms that further cluster and activate MuSK (see Discussion).

Nonetheless, the $M u S K$ promoter is required to maintain muscle prepatterning, since AChR clusters are ultimately scattered throughout most of the muscle by E18.5 in mice that carry the HSA::MuSK-L transgene and lack motor neurons and endogenous MuSK (Figure 6F). These data indicate that different mechanisms initiate and maintain muscle prepatterning, as regulatory elements in the $\mathrm{MuSK}$ promoter are required to maintain but not to establish muscle prepatterning.

\section{Ectopic MuSK promotes synapse formation in the absence of Agrin}

We demonstrated that high, ectopic $M u S K$ expression dictates where motor axons grow and form synapses. We considered the possibility that Agrin, released from motor axons, as they approach and explore muscle in $M u S K-H$ mice, was required to activate ectopic MuSK and stimulate postsynaptic and presynaptic differentiation. To test this idea, we crossed the $M u S K-H$ or $M u S K-L$ transgene into mice that lack either neural Agrin or all isoforms of Agrin, and we examined AChR clustering and motor innervation. As described previously (Gautam et al., 1996), few AChR clusters are present in agrin mutant mice at E18.5, and most of these AChR clusters are not innervated (Figure 7A, B, G, H). In contrast, in agrin mutant mice that carry either the $M u S K-H$ (Figure 7C, D) or $M u S K-L$ transgene (Figure 7E, F, I, J), AChR clusters are abundant and found throughout the muscle of E18.5 mice. Further, a large number of these AChR clusters are contacted by motor axons (Figure S5), which terminate and arborize in a manner that appears identical to motor axon terminals in wild-type mice (inset in Figure 7D, F, J). Importantly, both the MuSK-H and MuSK-L transgenes rescue the neonatal lethality of mutant mice that lack neural Agrin (Figure $7 \mathrm{~K}$ ) or 
all Agrin isoforms (data not shown), demonstrating that these synapses are functional. Although the rescued agrin mutant mice are runted, they breathe and survive for several weeks postnatally (Figure 7K). These findings indicate that increasing the level of $M u S K$ expression, as little as 3-fold, is sufficient to form synapses independent of Agrin and to counteract dispersion of AChR clusters by ACh (see Discussion).

\section{Discussion}

Different classes of neurons exhibit a characteristic pattern of axon branching within their target field, leading to a stereotyped pattern of innervation within the appropriate layer or lamina. The roles of incoming presynaptic axons and postsynaptic target neurons in establishing this stereotyped pattern of axon growth and synapse formation are poorly understood. Our findings raise the possibility that regional differences in target fields, established prior to innervation, may have a general role in shaping axon growth and branching in the peripheral and central nervous systems.

Recent studies have demonstrated that muscle is pre-specialized in the central, prospective synaptic region prior to and independent of innervation, and these findings have led to a revised view of the steps and mechanisms that regulate neuromuscular synapse formation (Flanagan-Steet et al., 2005; Lin et al., 2001; Panzer et al., 2006; Yang et al., 2001; Yang et al., 2000). Key features of postsynaptic differentiation are established in a muscleautonomous, MuSK-dependent manner and motor neurons refine and sharpen, rather than induce this prepattern of postsynaptic differentiation.

Here, we find that $M u S K$ expression is itself prepatterned in muscle, suggesting that the pattern of MuSK activity may establish the muscle prepattern and regulate the pattern of innervation. We tested this idea by overexpressing $M u S K$ uniformly throughout the muscle and found that high, ectopic $M u S K$ expression alters the muscle prepattern and induces AChR clustering throughout the muscle. Moreover, we show that motor axons recognize the disturbed prepattern by growing and forming synapses throughout the muscle. Thus, the muscle prepattern is recognized by approaching motor axons, shaping their growth and promoting synapse formation in the central region of the muscle. Further, we demonstrate that ectopic $M u S K$ expression is sufficient to induce synapse formation independent of Agrin and to rescue the neonatal lethality of agrin mutant mice. Thus, MuSK is sufficient to regulate the pattern of axon growth and to induce presynaptic and postsynaptic differentiation. Finally, our experiments provide insight into the mechanisms that establish muscle prepatterning. We find that a lower level of exogenous $M u S K$ expression, conferred by a heterologous promoter that is activated early during muscle differentiation but ultimately expressed uniformly in muscle, is sufficient to establish muscle prepatterning. These data suggest that the timing and level, rather than the pattern of MuSK expression have a critical role in initiating muscle prepatterning. Below, we discuss the implications of these findings: first, the role of muscle prepatterning in shaping motor axon growth and regulating the pattern of innervation; second, how MuSK may direct synapse formation in the absence of Agrin; third, how the timing and level of $M u S K$ expression may play a critical role in establishing and sustaining the muscle prepattern.

\section{The role of muscle prepatterning in shaping motor axon growth and regulating the pattern of innervation}

We found that high levels of ectopic MuSK expression in developing muscle induces ectopic AChR clusters, consistent with previous studies which demonstrated that ectopic expression of MuSK in adult myofibers induces ectopic AChR clustering and transcription (Fu et al., 2001; Hesser et al., 1999; Jones et al., 1999; Sander et al., 2001). Here, we find that ectopic overexpression of $\mathrm{MuSK}$ alters the pattern of motor axon growth and synapse formation, 
since motor axons grow and form synapses aberrantly throughout the muscle of mice that carry the $M u S K-H$ transgene. These findings demonstrate that $M u S K$ misexpression disrupts the AChR prepattern and indicate that approaching motor axons normally recognize and respond to the MuSK-dependent muscle prepattern. Consistent with these findings, live imaging of neuromuscular synapse formation in zebrafish suggested that motor axons sense and turn toward prepatterned AChR clusters (Flanagan-Steet et al., 2005; Panzer et al., 2006); our studies demonstrate that motor axons recognize a MuSK-dependent prepattern and are re-routed when the pattern of MuSK expression is altered. Further studies will be necessary to identify the signaling events downstream from MuSK that lead to the production of cell surface and/or secreted proteins that shape motor axon growth and promote synapse formation.

\section{MuSK is sufficient to promote synapse formation in the absence of Agrin}

Motor axons provide two signals that act in an opposing manner to modify and sharpen the AChR prepattern (Lin et al., 2001; Yang et al., 2001). Agrin stimulates MuSK and stabilizes postsynaptic differentiation, whereas ACh stimulates AChRs and destabilizes AChR clusters that are not apposed by nerve terminals (Lin et al., 2005; Misgeld et al., 2005). In agrin mutant mice, motor neurons fail to provide Agrin, so prepatterned AChR clusters are extinguished by ACh (Lin et al., 2005; Misgeld et al., 2005). In ChAT mutant mice, which fail to synthesize ACh, non-synaptic AChR clusters are not dispersed, so non-synaptic, prepatterned AChR clusters persist while synaptic AChR clusters are stabilized. The mechanisms by which these two signaling pathways converge are poorly understood, but the combination of these two signals, one promoting and one extinguishing AChR clusters, leads to the selective stabilization of postsynaptic differentiation at nascent synapses (Lin et al., 2005; Misgeld et al., 2005). Our studies show that MuSK overexpression alters this balancing act, since non-synaptic AChR clusters are not extinguished but are maintained in mice that lack Agrin and overexpress MuSK. Taken together with experiments showing that the AChR prepattern is maintained in agrin mutant mice that fail to synthesize ACh (Lin et al., 2005; Misgeld et al., 2005), these studies demonstrate a fine balancing act between the signaling pathways mediated by Agrin/MuSK, which stabilizes the muscle prepattern, and $\mathrm{ACh} / \mathrm{AChRs}$, which destabilizes the prepattern.

Surprisingly, neuromuscular synapses form and function in mice that lack Agrin and express a low- or high-expressing $M u S K$ transgene. Moreover, unlike agrin mutant mice, which fail to form synapses and die at birth, these mice survive postnatally. These studies demonstrate that Agrin per se is not required to form functional synapses in vivo and support the idea that the role of Agrin in neuromuscular synapse formation is to enhance MuSK signaling in the context of opposing signals that act to extinguish synapses. Although we cannot exclude the possibility that a ligand, other than Agrin, activates MuSK, previous studies have shown that MuSK, like other receptor tyrosine kinases, can be activated in a ligand-independent manner in transfected cells that overexpress MuSK and in transfected adult myofibers (Hesser et al., 1999; Jones et al., 1999; Sander et al., 2001). Moreover, nerve-independent AChR clustering, unlike AChR clustering at synapses, is strikingly sensitive to MuSK dosage, consistent with the idea that muscle prepatterning is established by ligand-independent MuSK activation (Lin et al., 2001). Thus, ligand-independent activation of MuSK may be sufficient to trigger presynaptic and postsynaptic differentiation in vivo. In either case, it is striking that MuSK activation, independent of Agrin, is sufficient in vivo to restore the formation of functional synapses and to rescue the lethality of agrin mutant mice. Importantly, these studies demonstrate that synapse formation is critically dependent upon MuSK but does not require an adhesive interaction between Agrin and MuSK for motor axons to stop and differentiate (Campagna et al., 1995; Dimitropoulou and Bixby, 2005). 


\section{The timing of MuSK expression may play a critical role in establishing the muscle prepattern}

In the absence of motor neurons and endogenous MuSK, AChRs are expressed uniformly in skeletal muscle. Strikingly, uniform expression of $M u S K$ from an actin::MuSK transgene restores AChR patterning to muscles that would otherwise lack any sign of regional specialization. Our findings are consistent with the idea that early $M u S K$ expression, conferred by the $\alpha$-actin promoter, leads to stochastic dimerization and activation of MuSK protein, which is reinforced by positive feedback mechanisms, leading to further MuSK activation in the central region of muscle where MuSK is first expressed (Figure 6H, I). Although our data do not exclude other models for transforming a uniform pattern of MuSK RNA expression to a spatially restricted pattern of MuSK kinase activity, this temporal model is the most parsimonious and takes account of known properties of MuSK, including positive feedback regulation, and the spatial pattern of muscle growth.

Our data indicate that transcriptional mechanisms, however, are required to maintain and stabilize the muscle prepattern, since in mice that lack motor neurons and endogenous MuSK but carry the MuSK-L transgene, AChR clusters are ultimately scattered throughout most of the muscle at later developmental stages (Figure 6F). Since activated MuSK stimulates MuSK transcription (Moore et al., 2001), these data suggest that a positive-feedback transcriptional loop may have a critical role in stabilizing the muscle prepattern. A better understanding of the transcriptional mechanisms that regulate $M u S K$ expression will be necessary to determine how muscle prepatterning is maintained and how synapses are stabilized.

\section{Experimental Procedures}

\section{Generation of HSA::MUSK transgenic mice}

The HSA promoter/exon1/intron cassette $(-2000 /+234)$ was excised from pHSA2000CAT (Brennan and Hardeman, 1993; Muscat and Kedes, 1987) by digestion with HindIII, and the blunt-ended fragment was subcloned into the StuI site of pSG5 (Stratagene). Rat MuSKGFP cDNA was excised from L29/MuSK-FLAG-GFP (Herbst et al., 2002) with EcoRI and subcloned into pSG5, containing the HSA promoter cassette. The HSA::MuSK sequence, as well as the linked rabbit $\beta$-globin intron and SV40 polyadenylation signal, were released from the pSG5 plasmid, using SfiI and XmnI, and the gel-purified fragment was injected into zygotic male pronuclei, as described previously (Simon et al., 1992). Founder mice and F1 progeny were genotyped by PCR. We obtained four founder mice and generated three lines. We studied two lines, a MuSK-L line, which express 3-fold more MuSK than wild-type mice, and a MuSK-H line, which overexpresses MuSK by 20 -fold (Figure 1); a third line expressed the transgene at very low levels and was not studied further.

\section{Mouse strains and genotyping}

$H S A:: M u S K$ (MuSK-H or MuSK-L) mice were genotyped by PCR, as described previously for MCK::MuSK mice (Herbst et al., 2002). HB9cre and Is $2^{D T A}$ mice have been described previously (Arber et al., 1999; Yang et al., 2001) and were genotyped by PCR (HB9 ${ }^{\text {cre }}$ : 5'CCGGTGAACGTGCAAAACAGGCTCTA-3' and 5'CTTCCAGGGCGCGAGTTGATAGC-3'; Is $l 2^{\text {DTA }}$ : 5'-ACGACGCTGCGGGATACTCT-3' and $5^{\prime}$-CAACGCTAGAACTCCCCTCA-3'). MuSK mutant mice were genotyped by PCR, as described previously (DeChiara et al., 1996; Herbst et al., 2002). Agrin ${ }^{\Delta Z}$ mice, lacking neural Agrin (Gautam et al., 1996), were genotyped by PCR (5'GTCAGTGGGGGACCTAGAAAC-3' and 5'-GTTGCTCTGCAGCGCCTT-3'). Agrin null mice, lacking all Agrin isoforms (Lin et al., 2001), were genotyped by PCR (5'GGGCTAACACCAACAACAATGCAACAAAGG-3' and 5'- 
TGCCAAGTTCTAATTCCATCAGAAGCTGAC-3'), as described previously (Lin et al., 2001). All experiments described here were approved by the Animal Care and Use Committee at NYU Medical School.

\section{Immunohistochemistry}

Dissected diaphragm muscles were fixed (1\% formaldehyde in phosphate buffered saline) (PBS) for 90 min at room temperature and further fixed ( $0.2 \%$ formaldehyde in PBS) overnight at $4{ }^{\circ} \mathrm{C}$. Muscles were washed three times for $15 \mathrm{~min}$ in PBS, incubated for $15 \mathrm{~min}$ with $100 \mathrm{mM}$ glycine in PBS and rinsed in PBS. Overlying connective tissue was carefully removed, and muscles were permeabilized and blocked for $1 \mathrm{~h}$ in PBS containing $2 \%$ bovine serum albumin, $4 \%$ normal goat serum and $0.5 \%$ Triton X-100. Axons and nerve terminals were labeled by staining muscles overnight at $4{ }^{\circ} \mathrm{C}$ with rabbit polyclonal antibodies against NF (1:2000; Chemicon, Temecula, CA) and Syn (1:5; Zymed, San Francisco, CA) in blocking solution. After three $1 \mathrm{~h}$ washes in PBS, containing 0.5\% Triton X-100 (PBT), muscles were incubated at $4^{\circ} \mathrm{C}$ overnight with Alexa-488 goat anti-rabbit $\operatorname{IgG}(1: 250$; Invitrogen) and Alexa-594-conjugated- $\alpha$-BGT (1:1000; Invitrogen, San Diego, CA) in blocking solution, to label AChRs. After three $1 \mathrm{~h}$ washes in PBT and one 20 min wash in PBS, muscles were post-fixed (1\% formaldehyde in PBS) for 10 min, rinsed in PBS and mounted under glass in Vectashield (Vector Labs, Burlingame, CA).

\section{Quantification of axon growth and $\mathrm{AChR}$ cluster distribution}

Diaphragm muscles from P0 wild-type, $M u S K-L$ and $M u S K-H$ mice were stained with antibodies to NF and Syn and Alexa-594- $\alpha$-BGT. Confocal images of the left hemidiaphragm were captured on a Zeiss 510 confocal laser scanning microscope (Carl Zeiss MicroImaging $\mathrm{GmbH}$, Jena, Germany). These image stacks were compiled into a reconstructed image of the left hemi-diaphragm muscle. To measure the distribution of AChR clusters and axons within the muscle, we divided this reconstructed image into nine $100 \mu \mathrm{m}$ wide strips, oriented parallel to the main intramuscular nerve; strip 1 was the most costal strip, strip 5 was centered over the main intramuscular nerve, and strip 9 was the most medial strip. The number of pixels in each strip (green channel for axons and red channel for AChRs) was determined using Metamorph (Molecular Devices, Sunnyvale, CA). The number of pixels in the central, synaptic strip (strip 5) was assigned a value of $100 \%$, and the values in other strips are expressed relative to strip 5. Data were collected from four or more diaphragm muscles from each genotype.

\section{Quantification of synapse size and distribution}

We collected stacks of overlapping, confocal images, extending from the medial to the costal edge of the left hemi diaphragm muscle in P0 wild-type and $M u S K-H$ mice. Following assembly of these image sets, we measured the number and position of synapses in the muscle. Reconstructed images were divided into 15 strips, and the number of synapses and non-synaptic AChR clusters were determined within each strip. Data were collected from three or more diaphragm muscles from each genotype.

AChR cluster size and density was measured, as described previously (Herbst et al., 2002; Jaworski and Burden, 2006). Briefly, we stained P0 diaphragm muscle from wild-type, $M u S K-H$ and $M u S K-L$ mice with Alexa-594- $\alpha-B G T$, and collected confocal image stacks at the same subsaturating amplifier gain for all genotypes. The data was quantified using Volocity 3D software (Improvision, Lexington, MA). At least 70 synapses in each P0 embryo from at least 4 animals per genotype were analyzed. 


\section{Quantification of AChR clusters in dissociated myofibers}

Single muscle fibers were isolated from diaphragm and extensor digitorum longus muscles from P0 wild-type and $\mathrm{MuSK}-\mathrm{H}$ mice by digestion with collagenase $(0.2 \% \mathrm{w} / \mathrm{v})$ at $37^{\circ} \mathrm{C}$ for 30 min (Shefer and Yablonka-Reuveni, 2005). After washing in PBS, the dissociated muscle fibers were fixed (1\% paraformaldehyde) for $30 \mathrm{~min}$ at room temperature, washed in PBS and stained with Alexa-594- $\alpha$-BGT and Alexa-660-phalloidin, to label AChRs and myofibers. Images of the stained, individual muscle fibers were captured by confocal microscopy, and the number of AChR clusters per muscle cell was determined. We examined 200 to 400 single fibers from each muscle and at least three mice for each genotype.

\section{Whole mount in situ-hybridization}

Intercostal muscles from wild-type, $M u S K-L$ and $M u S K-H$ mice were fixed (4\% formaldehyde in PBS) overnight at $4^{\circ} \mathrm{C}$, dehydrated in methanol, digested for 30 min with $20 \mu \mathrm{g} / \mathrm{ml}$ proteinase $\mathrm{K}$, hybridized with digoxigenin-labeled riboprobes directed against mRNAs encoding the AChR $\delta$ subunit (Simon et al., 1992) or MuSK (Herbst et al., 2002) and processed as described previously (Yang et al., 2001). Weak, uniform staining was observed with sense probe for $A C h R \delta$ subunit and $M u S K$ (data not shown).

\section{Quantitative real time PCR}

Diaphragm muscles were homogenized on ice in RNA STAT-60 (Tel-Test, Friendswood, TX) using a PT 10/35 Polytron (Kinematica AG, Littau-Lucerne, Switzerland), and total RNA was isolated according to the manufacturer's instructions. After treatment with DNase I for $15 \mathrm{~min}$ at $37^{\circ} \mathrm{C}, 200 \mathrm{ng}$ of RNA was reverse transcribed (RT) using the iScript cDNA synthesis kit (Bio-Rad, Hercules, CA). Quantitative PCR was performed using iQ SYBR Green Supermix (Bio-Rad, Hercules, CA) on an Opticon 2 real-time thermocycler (Bio-Rad Hercules, CA), using 5 percent of each RT reaction. The primers used for PCR amplification (Figure 1F), which amplify RNA transcribed from the endogenous $M u S K$ gene as well as the MuSK transgene, were: 5'-CCCTGCAAGTGAAGATGAAA-3' and 5'-

TTCAAGAACTGCGATTCTGG-3' for MuSK, as described previously (Jaworski and Burden, 2006), and 5'-CGTGTCACCTCTGCTGCT-3' and 5'-

CCTTCATATTGCCTCCCTTCT-3' for muscle creatine kinase (mck) (Jaworski, unpublished data). $M u S K$ expression was normalized to $m c k$ expression. The linearity of the real time PCR reaction was confirmed by analyzing serial dilutions of samples, and each reaction was performed at least in duplicate. Expression levels were determined from at least four animals for each genotype.

\section{Quantification of myotube size}

To analyze the number and size of myofibers, diaphragm muscles from P0 wild-type and $M u S K-H$ mice were immersion-fixed (in $1 \%$ glutaraldehyde and $4 \%$ paraformaldehyde in $0.1 \mathrm{M}$ sodium phosphate, $\mathrm{pH}$ 7.2) for $90 \mathrm{~min}$ at room temperature, washed three times with isoosmotic phosphate buffer, washed three times in $0.1 \mathrm{M}$ Tris, $\mathrm{pH} \mathrm{7.2,} \mathrm{and} \mathrm{treated} \mathrm{for} 1 \mathrm{~h}$ in $1 \%$ osmium. After a $1 \mathrm{~h}$ wash in water, diaphragm muscles were dehydrated in ethanol and embedded in Epon. For light microscopy, cross sections of anatomically matched areas of the diaphragm muscle were stained with toluidine blue, and images were captured on a Sony DKC-500 camera. The cross-sectional area of individual myofibers was measured using NIH ImageJ, and the number of muscle fibers in a defined area of the diaphragm muscle was counted. Myofiber number and size were determined from at least 3 animals for each genotype. 


\section{Quantification of spinal motor neurons}

Spinal cords from P0 wild-type and $M u S K-H$ mice were fixed (4\% formaldehyde in PBS) at room temperature for $2 \mathrm{~h}$, washed three times in cold PBS, equilibrated in $15 \%$ sucrose in PBS for $2 \mathrm{~h}$ at room temperature, followed by equilibration in $30 \%$ sucrose in PBS overnight at $4{ }^{\circ} \mathrm{C} .10 \mu \mathrm{m}$ frozen sections from the cervical, thoracic and lumbar spinal segments were collected and stained with a rabbit polyclonal antibody against Islet1/2 (CU321). The number of Islet1/2-positive neurons, located in the ventro-lateral portion of the spinal cord, from cervical, thoracic and lumbar segments was counted in every third section. We examined spinal cord sections from at least three animals for each genotype.

\section{Supplementary Material}

Refer to Web version on PubMed Central for supplementary material.

\section{Acknowledgments}

We are grateful to Tom Jessell for kindly providing antibodies to Islet $1 / 2$ as well as $H B 9^{c r e}$ mice and $I s l 2^{D T A}$ mice, Josh Sanes for kindly providing agrin $\triangle Z$ and agrin null mice, and Edna Hardeman for kindly providing pHSA2000CAT. We thank Jihua Fan for excellent technical assistance, and Jeremy Dasen, Wenbiao Gan and Dan Littman for their comments on the manuscript. This work was supported with funds from the NIH and the Robert Packard Center for ALS Research.

\section{References}

Arber S, Burden SJ, Harris AJ. Patterning of skeletal muscle. Curr Opin Neurobiol 2002;12:100-103. [PubMed: 11861171]

Bennett MR, Pettigrew AG. The formation of synapses in striated muscle during development. J Physiol 1974;241:515-545. [PubMed: 4443927]

Bennett MR, Pettigrew AG. The formation of neuromuscular synapses. Cold Spring Harb Symp Quant Biol 1976;40:409-424. [PubMed: 1065534]

Brennan KJ, Hardeman EC. Quantitative analysis of the human alpha-skeletal actin gene in transgenic mice. J Biol Chem 1993;268:719-725. [PubMed: 7678010]

Burden SJ. The formation of neuromuscular synapses. Genes Dev 1998;12:133-148. [PubMed: 9436975]

Campagna JA, Ruegg MA, Bixby JL. Agrin is a differentiation-inducing "stop signal” for motoneurons in vitro. Neuron 1995;15:1365-1374. [PubMed: 8845159]

DeChiara TM, Bowen DC, Valenzuela DM, Simmons MV, Poueymirou WT, Thomas S, Kinetz E, Compton DL, Rojas E, Park JS, et al. The receptor tyrosine kinase MuSK is required for neuromuscular junction formation in vivo. Cell 1996;85:501-512. [PubMed: 8653786]

Dimitropoulou A, Bixby JL. Motor neurite outgrowth is selectively inhibited by cell surface MuSK and agrin. Mol Cell Neurosci 2005;28:292-302. [PubMed: 15691710]

Flanagan-Steet H, Fox MA, Meyer D, Sanes JR. Neuromuscular synapses can form in vivo by incorporation of initially aneural postsynaptic specializations. Development 2005;132:4471-4481. [PubMed: 16162647]

Fontaine B, Sassoon D, Buckingham M, Changeux JP. Detection of the nicotinic acetylcholine receptor alpha-subunit mRNA by in situ hybridization at neuromuscular junctions of 15-day-old chick striated muscles. Embo J 1988;7:603-609. [PubMed: 3396533]

Fu AK, Cheung J, Smith FD, Ip FC, Ip NY. Overexpression of muscle specific kinase increases the transcription and aggregation of acetylcholine receptors in Xenopus embryos. Brain Res Mol Brain Res 2001;96:21-29. [PubMed: 11731005]

Gautam M, Noakes PG, Moscoso L, Rupp F, Scheller RH, Merlie JP, Sanes JR. Defective neuromuscular synaptogenesis in agrin-deficient mutant mice. Cell 1996;85:525-535. [PubMed: 8653788] 
Glass DJ, Bowen DC, Stitt TN, Radziejewski C, Bruno J, Ryan TE, Gies DR, Shah S, Mattsson K, Burden SJ, et al. Agrin acts via a MuSK receptor complex. Cell 1996a;85:513-523. [PubMed: 8653787]

Glass DJ, DeChiara TM, Stitt TN, DiStefano PS, Valenzuela DM, Yancopoulos GD. The receptor tyrosine kinase MuSK is required for neuromuscular junction formation and is a functional receptor for agrin. Cold Spring Harb Symp Quant Biol 1996b;61:435-444. [PubMed: 9246472]

Glass DJ, Yancopoulos GD. Sequential roles of agrin, MuSK and rapsyn during neuromuscular junction formation. Curr Opin Neurobiol 1997;7:379-384. [PubMed: 9232805]

Herbst R, Avetisova E, Burden SJ. Restoration of synapse formation in Musk mutant mice expressing a Musk/Trk chimeric receptor. Development 2002;129:5449-5460. [PubMed: 12403715]

Hesser BA, Sander A, Witzemann V. Identification and characterization of a novel splice variant of MuSK. FEBS Lett 1999;442:133-137. [PubMed: 9928988]

Jaworski A, Burden SJ. Neuromuscular synapse formation in mice lacking motor neuron- and skeletal muscle-derived Neuregulin-1. J Neurosci 2006;26:655-661. [PubMed: 16407563]

Jones G, Moore C, Hashemolhosseini S, Brenner HR. Constitutively active MuSK is clustered in the absence of agrin and induces ectopic postsynaptic-like membranes in skeletal muscle fibers. J Neurosci 1999;19:3376-3383. [PubMed: 10212297]

Kandel, ER.; Schwartz, JH.; Jessell, TM. Principles of neural science. 4. New York: McGraw-Hill, Health Professions Division; 2000.

Lacazette E, Le Calvez S, Gajendran N, Brenner HR. A novel pathway for MuSK to induce key genes in neuromuscular synapse formation. J Cell Biol 2003;161:727-736. [PubMed: 12756238]

Lin W, Burgess RW, Dominguez B, Pfaff SL, Sanes JR, Lee KF. Distinct roles of nerve and muscle in postsynaptic differentiation of the neuromuscular synapse. Nature 2001;410:1057-1064. [PubMed: 11323662]

Lin W, Dominguez B, Yang J, Aryal P, Brandon EP, Gage FH, Lee KF. Neurotransmitter acetylcholine negatively regulates neuromuscular synapse formation by a Cdk5-dependent mechanism. Neuron 2005;46:569-579. [PubMed: 15944126]

Minty AJ, Alonso S, Caravatti M, Buckingham ME. A fetal skeletal muscle actin mRNA in the mouse and its identity with cardiac actin mRNA. Cell 1982;30:185-192. [PubMed: 6897014]

Misgeld T, Kummer TT, Lichtman JW, Sanes JR. Agrin promotes synaptic differentiation by counteracting an inhibitory effect of neurotransmitter. Proc Natl Acad Sci U S A 2005;102:1108811093. [PubMed: 16043708]

Moore C, Leu M, Muller U, Brenner HR. Induction of multiple signaling loops by MuSK during neuromuscular synapse formation. Proc Natl Acad Sci U S A 2001;98:14655-14660. [PubMed: 11717400]

Muscat GE, Kedes L. Multiple 5'-flanking regions of the human alpha-skeletal actin gene synergistically modulate muscle-specific expression. Mol Cell Biol 1987;7:4089-4099. [PubMed: 2828926]

Nguyen QT, Lichtman JW. Mechanism of synapse disassembly at the developing neuromuscular junction. Curr Opin Neurobiol 1996;6:104-112. [PubMed: 8794054]

Panzer JA, Song Y, Balice-Gordon RJ. In vivo imaging of preferential motor axon outgrowth to and synaptogenesis at prepatterned acetylcholine receptor clusters in embryonic zebrafish skeletal muscle. J Neurosci 2006;26:934-947. [PubMed: 16421313]

Sander A, Hesser BA, Witzemann V. MuSK induces in vivo acetylcholine receptor clusters in a ligand-independent manner. J Cell Biol 2001;155:1287-1296. [PubMed: 11748247]

Sanes JR, Lichtman JW. Development of the vertebrate neuromuscular junction. Annu Rev Neurosci 1999;22:389-442. [PubMed: 10202544]

Sanes JR, Lichtman JW. Induction, assembly, maturation and maintenance of a postsynaptic apparatus. Nat Rev Neurosci 2001;2:791-805. [PubMed: 11715056]

Schaeffer L, de Kerchove d'Exaerde A, Changeux JP. Targeting transcription to the neuromuscular synapse. Neuron 2001;31:15-22. [PubMed: 11498047]

Shefer G, Yablonka-Reuveni Z. Isolation and culture of skeletal muscle myofibers as a means to analyze satellite cells. Methods Mol Biol 2005;290:281-304. [PubMed: 15361669] 
Simon AM, Hoppe P, Burden SJ. Spatial restriction of AChR gene expression to subsynaptic nuclei. Development 1992;114:545-553. [PubMed: 1618127]

Slater CR. Neural influence on the postnatal changes in acetylcholine receptor distribution at nervemuscle junctions in the mouse. Dev Biol 1982a;94:23-30. [PubMed: 7152105]

Slater CR. Postnatal maturation of nerve-muscle junctions in hindlimb muscles of the mouse. Dev Biol 1982b;94:11-22. [PubMed: 7152099]

Strochlic L, Cartaud A, Cartaud J. The synaptic muscle-specific kinase (MuSK) complex: new partners, new functions. Bioessays 2005;27:1129-1135. [PubMed: 16237673]

Valenzuela DM, Stitt TN, DiStefano PS, Rojas E, Mattsson K, Compton DL, Nunez L, Park JS, Stark JL, Gies DR, et al. Receptor tyrosine kinase specific for the skeletal muscle lineage: expression in embryonic muscle, at the neuromuscular junction, and after injury. Neuron 1995;15:573-584. [PubMed: 7546737]

Williams PE, Goldspink G. Longitudinal growth of striated muscle fibres. J Cell Sci 1971;9:751-767. [PubMed: 5148015]

Yang X, Arber S, William C, Li L, Tanabe Y, Jessell TM, Birchmeier C, Burden SJ. Patterning of muscle acetylcholine receptor gene expression in the absence of motor innervation. Neuron 2001;30:399-410. [PubMed: 11395002]

Yang X, Li W, Prescott ED, Burden SJ, Wang JC. DNA topoisomerase IIbeta and neural development. Science 2000;287:131-134. [PubMed: 10615047]

Zhang M, McLennan IS. During secondary myotube formation, primary myotubes preferentially absorb new nuclei at their ends. Dev Dyn 1995;204:168-177. [PubMed: 8589440] 

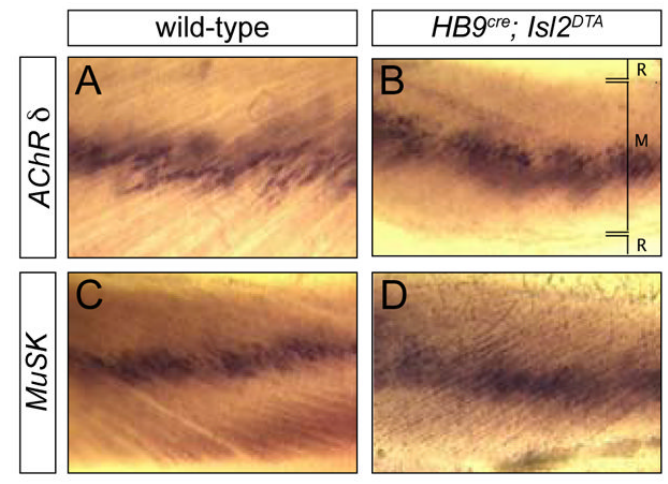

E HSA::MUSK
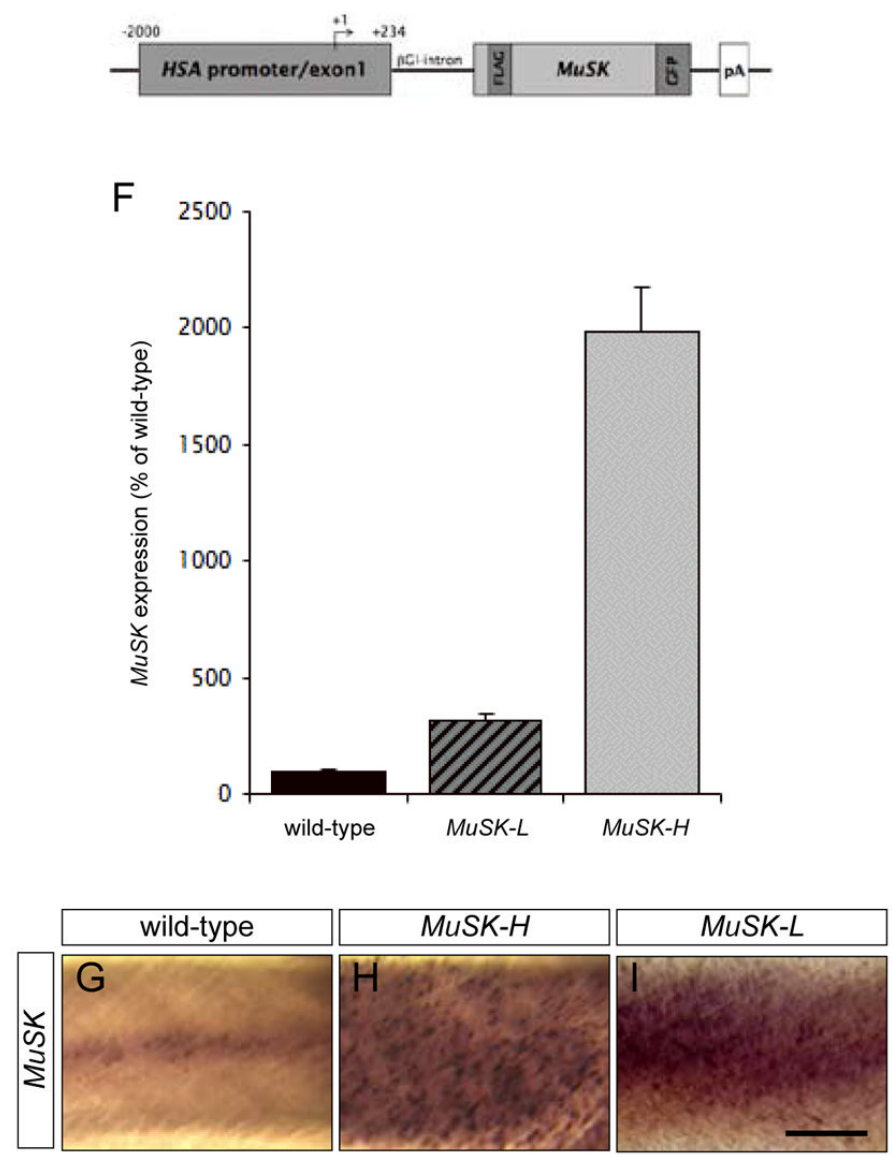

Figure 1. Endogenous MuSK expression is patterned independent of innervation whereas HSA::MuSK is expressed uniformly in skeletal muscle

(A-D) Whole mounts of intercostal muscles from E18.5 wild-type (A, C) and $H B 9^{\text {cre }}$; $I s l 2^{D T A}(\mathrm{~B}, \mathrm{D})$ embryos were processed for in situ-hybridization using probes for the $A C h R$ $\delta$ subunit and $M u S K$. MuSK mRNA (C, D) and $A C h R \delta$ mRNA (A, B) are concentrated in the central region of muscle from wild-type and $H B 9^{c r e}$; Is $l 2^{D T A}$ mice, demonstrating that expression of endogenous $M u S K$ is patterned in the absence of innervation. The positions of the ribs $(\mathrm{R})$ and muscle $(\mathrm{M})$ are indicated in B. (E) Schematic representation of the $H S A:: M u S K$ transgene. The human skeletal $\alpha$-actin 5 ' regulatory region was fused to a FLAG- and GFP-tagged MuSK cDNA. The FLAG tag was introduced into the extracellular 
domain of MuSK, and the GFP tag was added, in frame, to the MuSK carboxy terminus (Herbst et al. 2002). (F) The level of MuSK expression in two different HSA::MuSK transgenic lines was measured by real-time quantitative PCR. The low expressing line, $M u S K-L$, and the high expressing line, MuSK-H, express 3- and 20-fold more MuSK, respectively, than wild-type mice (MuSK-L: $311.29 \pm 31.8 \%$ of wild-type MuSK mRNA; MuSK-H: $1981.09 \pm 197.2 \%$ of wild-type MuSK $; \mathrm{n}=4$ mice for each genotype; the mean \pm S.E.M.). (G-I) Whole mounts of intercostal muscles from P0 wild-type, MuSK-H and $M u S K-L$ mice were processed for in situ hybridization to assess the pattern of $M u S K$ transcription. The endogenous $M u S K$ gene is transcribed selectively in the central, synaptic region of muscle $(\mathrm{G})$, while the $H S A$ regulatory region confers uniform $M u S K$ expression $(\mathrm{H}, \mathrm{I})$. Scale bar $=200 \mu \mathrm{m}$. 

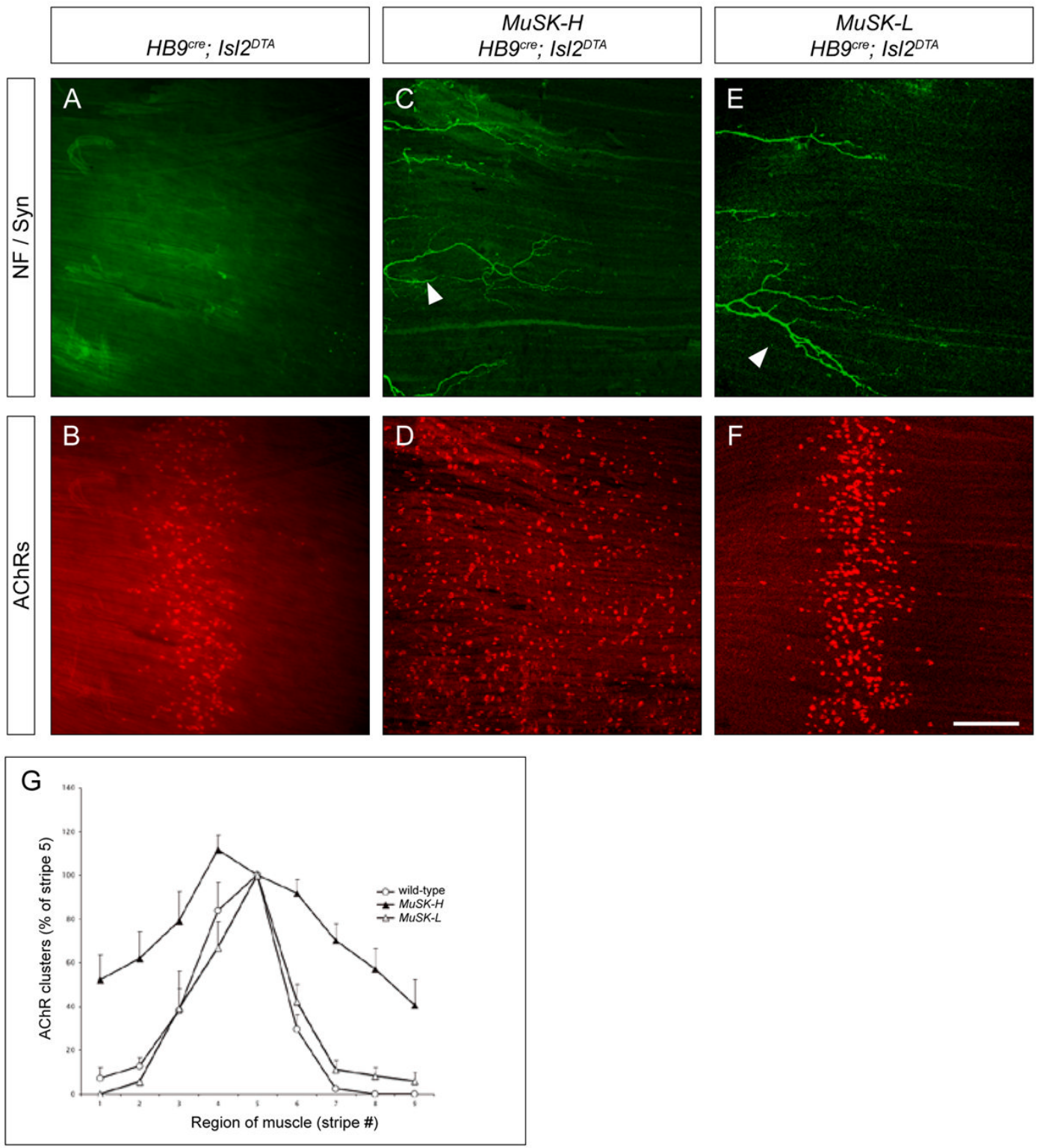

Figure 2. A high level of ectopic MuSK induces ectopic AChR clusters and disrupts AChR prepatterning

(A-F) Whole mounts of diaphragm muscles from E18.5 mice that lack motor axons (A, B) and from mice that lack motor axons and carry a $H S A: \because M u S K$ transgene (MuSK-H in $\mathrm{C}$ and $\mathrm{D} ; M u S K-L$ in E and F), were stained with Alexa594- $\alpha-\mathrm{BGT}$ (red) and antibodies to NF and Syn (green). Although motor axons are absent from muscle of $H B 9^{c r e}$; Isl2 ${ }^{D T A}$ mice, the axons of sensory and/or autonomic neurons (arrowheads) are found at their normal location at the periphery of the muscle (A, C, E). AChR clusters are concentrated in the central region of muscle from $H B^{9} 9^{c r e}$; Is $2^{D T A}$ mice (B) but expressed throughout the muscle of mice that lack motor innervation and carry the $M u S K-H$ transgene (D). Ectopic AChR clusters are not induced in muscle from mice that lack motor neurons and carry the $M u S K-L$ transgene $(\mathrm{F})$, showing that induction of ectopic AChR clusters is dependent upon the level of MuSK expression. (G) Quantitation of the distribution of AChR clusters (see Experimental Procedures). AChR clusters are concentrated in the central region of muscles from wild-type and $M u S K-L$ mice, while AChR clusters are distributed throughout the 
muscle of $M u S K-H$ mice $(\mathrm{m} \pm$ S.E.M., $\mathrm{n}=4$ mice for each genotype). Scale bar for A-F = $200 \mu \mathrm{m}$. 

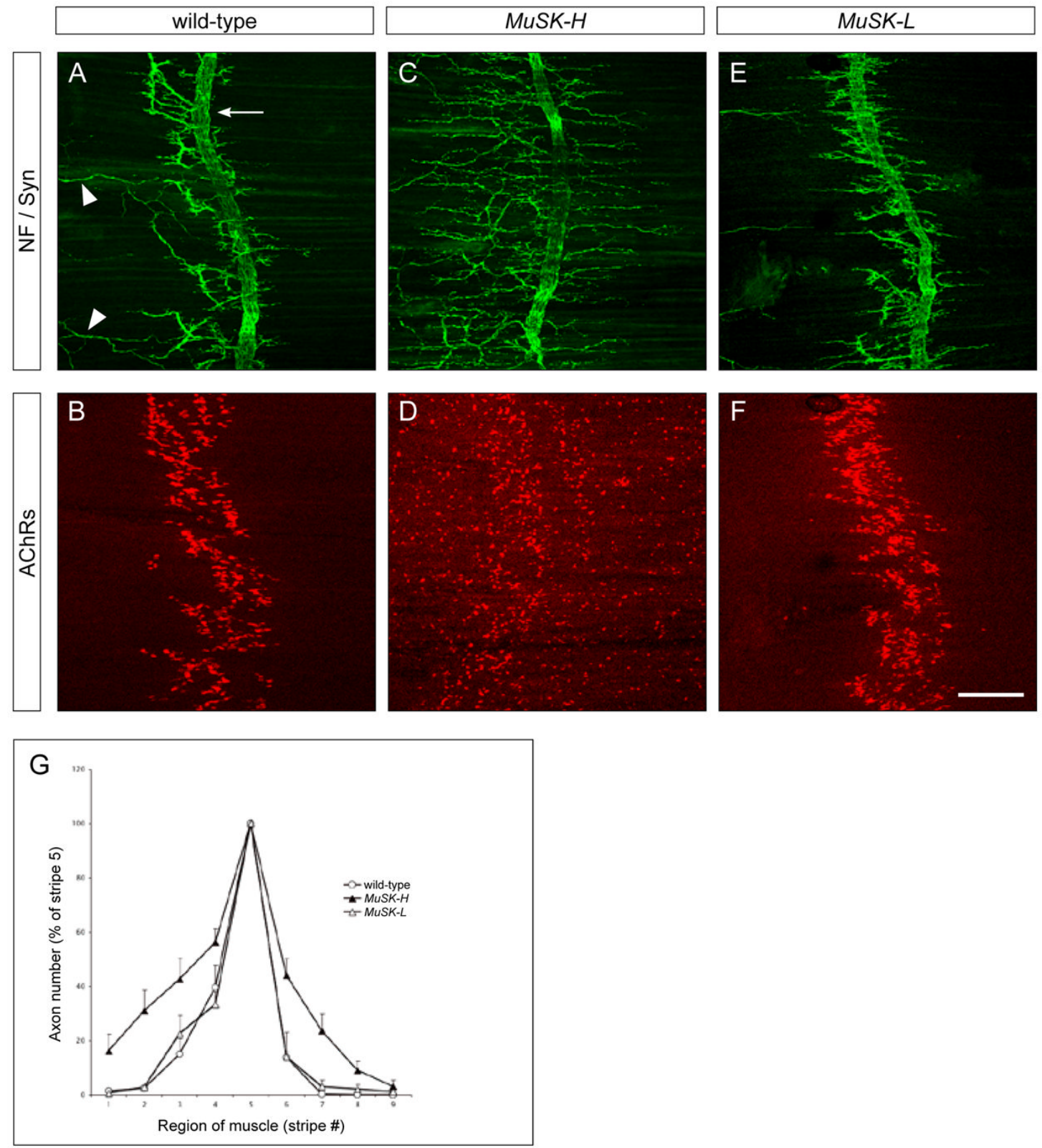

Figure 3. A high level of ectopic MuSK promotes motor axon outgrowth

In wild-type mice (A, B), motor axons are fasciculated near the middle of the muscle (arrow), whereas the axons of sensory and/or autonomic neurons (arrowheads) are found at the periphery of the muscle. In wild-type mice, motor axons branch and terminate adjacent to the main intramuscular nerve (A), and AChRs are clustered selectively at synaptic sites (B). In mice carrying the $M u S K-H$ transgene (C, D), the main intramuscular nerve is positioned correctly, but motor axons fail to stop and instead grow throughout the muscle (C). In contrast, in mice carrying the $M u S K-L$ transgene (E, F), the pattern of motor axon outgrowth is indistinguishable from wild-type mice (E). (G) Quantitation of motor axon growth (see Experimental Procedures). Motor axons in wild-type and $M u S K-L$ mice extend over $5-10 \%$ of the muscle, whereas motor axons in $M u S K-H$ mice grow over $90 \%$ of the muscle ( $m \pm$ S.E.M., $\mathrm{n}=4$ mice for each genotype). The expanded zone of axon growth 
found in P0 MuSK-H mice does not broaden further during postnatal development (Figure S1). Scale bar $=200 \mu \mathrm{m}$. 


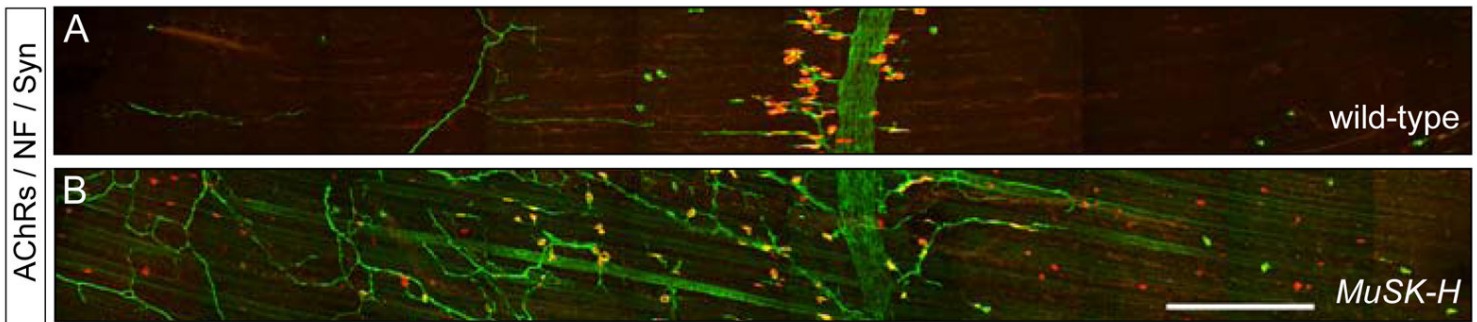

C

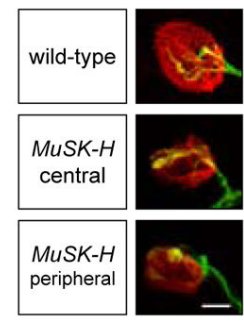

$\mathrm{F}$

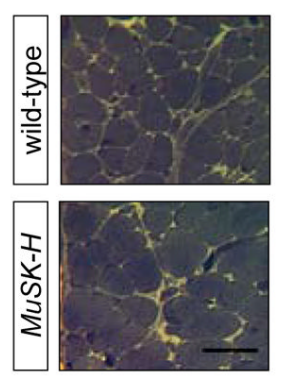

D

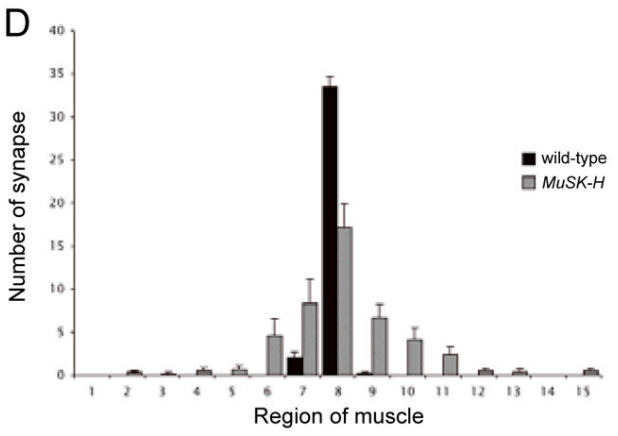

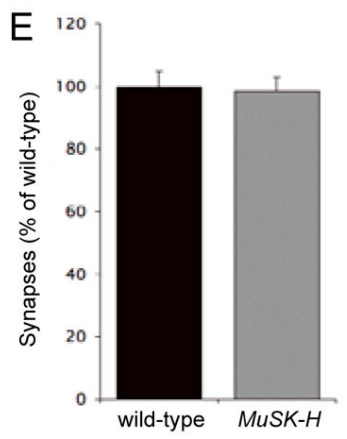

G

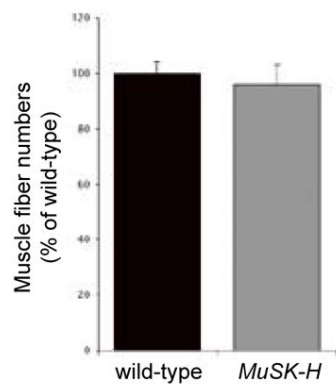

$\mathrm{H}$

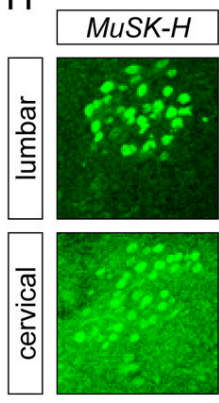

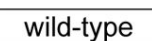
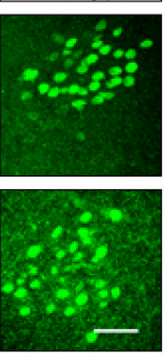
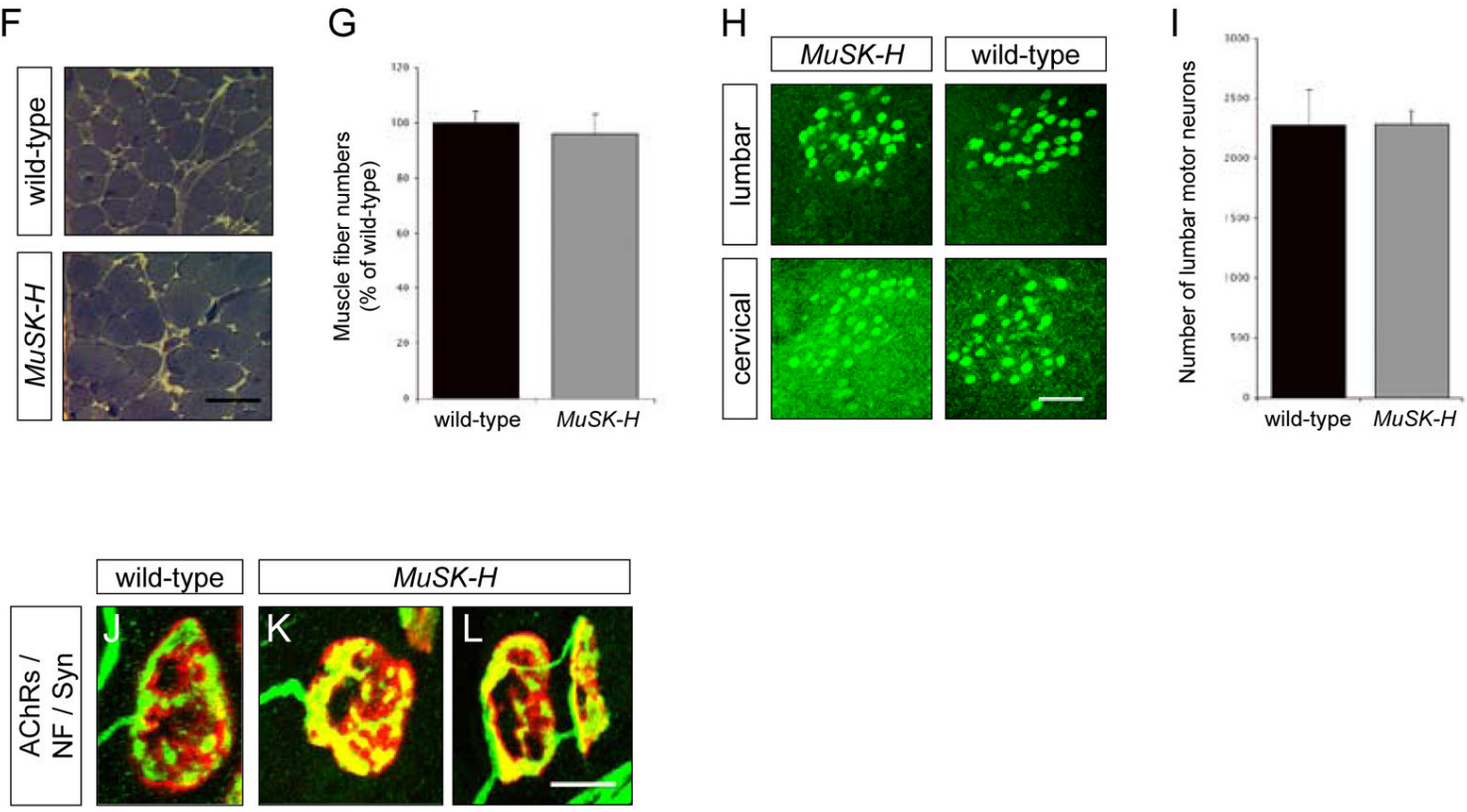

Figure 4. Ectopic MuSK induces ectopic synapses that arise from axon collateral branching (A-C) Whole mounts of diaphragm muscles from wild-type (A) and $M u S K-H$ (B) P0 mice were stained with Alexa594- $\alpha$-BGT (red) and antibodies to NF and Syn (green).

Anatomically matched areas from the left hemi-diaphragm were imaged from the medial to the costal edge of the muscle. In wild-type mice, synapses form only in the central region, adjacent to the main intramuscular nerve (A, D). In MuSK-H mice, synapses are distributed throughout the entire muscle (B, D). (C) Images of synapses in wild-type mice and in the central and peripheral regions of muscle from $M u S K-H$ mice show that the general structure of ectopic synapses in MuSK-H appears normal. (D) The distribution of synapses was quantitated by dividing the muscle into 15 strips, and the number of synapses in each strip 
was determined. In wild-type mice, synapses are concentrated in a narrow central band that covers 5 to $10 \%$ of the muscle, while in MuSK-H muscle synapses are distributed throughout $(\sim 90 \%)$ the muscle ( $\mathrm{m} \pm$ S.E.M., $\mathrm{n}=3$ mice for each genotype). (E) Muscle from $M u S K-H$ mice contains $28.76 \pm 3.7 \%$ (mean \pm S.E.M., $\mathrm{n}=3$ mice for each genotype) more synapses than muscle from wild-type mice. Synaptic size is lower in $M u S K-H$ mice than in wild-type mice, whereas synaptic AChR density is similar in wild-type and $M u S K-H$ mice (Figure S2). (F) Cross sections of diaphragm muscles from P0 MuSK-H and wild-type were stained with toluidine blue to count the number of muscle fibers. (G) The number of muscle fibers is similar in MuSK-H and wild-type mice (98.33 $\pm 4.6 \%$ of wild-type; $\mathrm{n}=3$ mice for each genotype; $\mathrm{m} \pm$ S.E.M.). (H) Frozen sections from the cervical or lumbar region of the spinal cord, were stained with antibodies to Islet1/2 (green), and the number of motor neurons was determined (Experimental Procedures). (I) The number of lumbar spinal motor neurons is similar in MuSK-H and wild-type mice, as shown for L1-L5 ( $\mathrm{n}=3$ mice for each genotype). The number of thoracic motor neurons is also similar in $M u S K-H$ and wild-type mice (Figure S3). (J, K, L) We examined 495 synapses in diaphragm muscles from P11 MuSK-H $(n=3)$ and observed 4 instances of terminal sprouting (L). In contrast, we did not find a single instance of terminal sprouting in wild-type muscle (J). Scale bar $=200 \mu \mathrm{m}$ for (A, B, F) and $10 \mu \mathrm{m}$ for $(\mathrm{C}, \mathrm{J}, \mathrm{K}, \mathrm{L})$ and $100 \mu \mathrm{m}$ for $(\mathrm{H})$. 

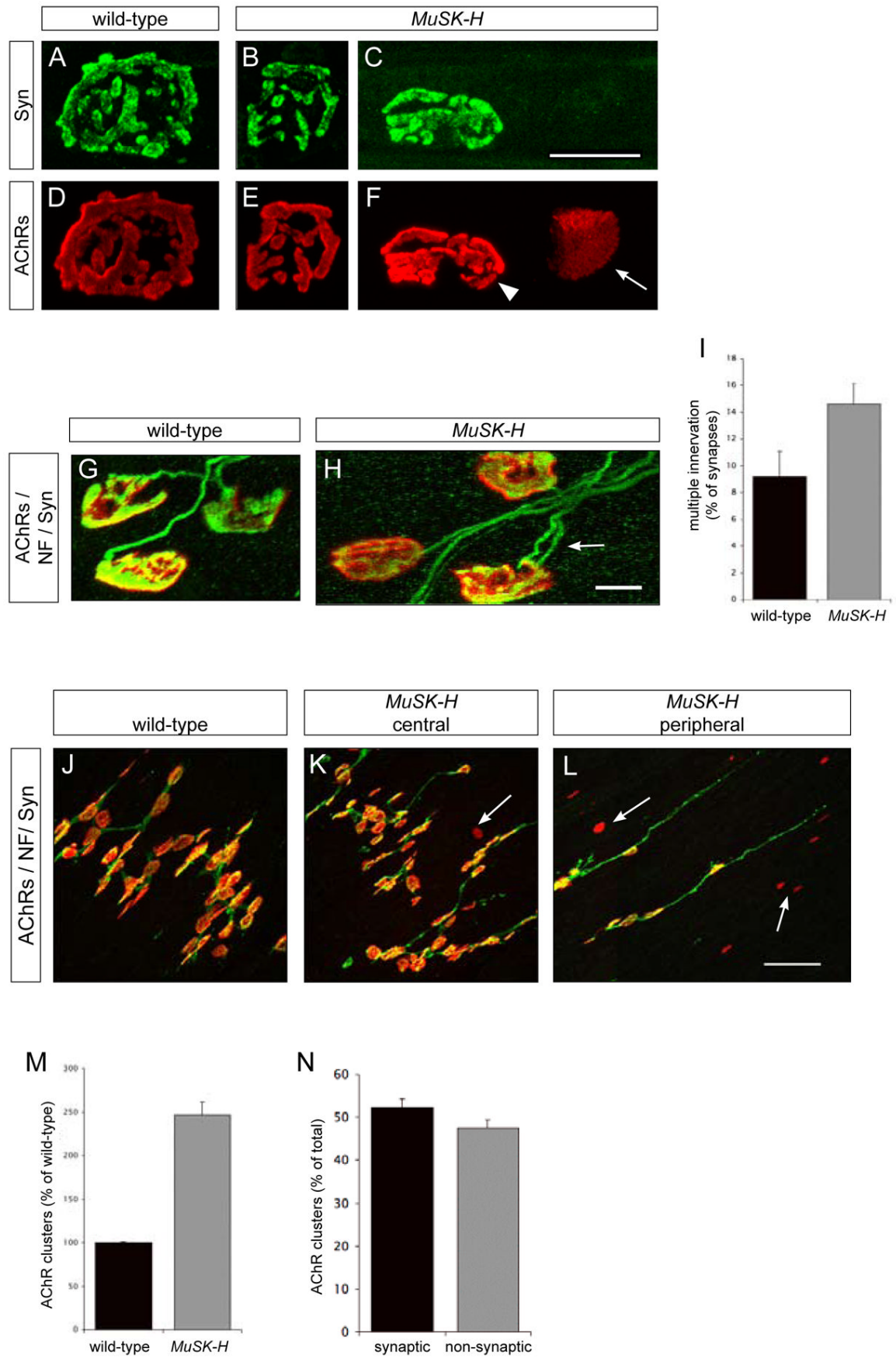

Figure 5. Synaptic AChR clusters mature, whereas ectopic, non-innervated AChR clusters remain simplified and are not extinguished in $\mathrm{MuSK}-\mathrm{H}$ mice

(A-L) Whole mounts of diaphragm muscles from P60 (A-F), P11 (G, H) and P0 (J, K, L) wild-type and $M u S K-H$ mice were stained with Alexa594- $\alpha$-BGT (red) and antibodies to NF and Syn (green). Synaptic AChR clusters mature normally in $M u S K-H$ mice, since they become perforated and highly branched (E), like in wild-type mice (D). Non-synaptic AChR clusters (arrow) do not mature but remain as ovoid plaques (arrowhead) (F). (G, H) Synapse elimination is delayed in $M u S K-H$ mice. The number of multiply-innervated synapses (arrow) in the diaphragm muscle is modestly greater in $M u S K-H$ than wild-type mice at P11 (H); by P30, all synapses are singly innervated in $M u S K-H$ and wild-type mice (data not 
shown). (I) At P11, $14.6 \% \pm 2 \%$ of synapses in $M u S K-H$ and $9.17 \% \pm 3.3 \%$ of synapses in wild-type mice are multiply-innervated ( $\mathrm{m} \pm$ S.E.M.). At least 140 synapses in 3 mice from each genotype were analyzed. (J, K, L) In P0 mice, non-innervated AChR clusters (arrows) are abundant in $M u S K-H$ mice and more prevalent in the peripheral (L) than in the central region of the muscle $(\mathrm{K})$. In contrast, all AChR clusters are innervated in muscle from $\mathrm{P} 0$ wild-type mice (J). (M) Muscle from MuSK-H mice express 2.5-fold more AChR clusters than wild-type mice ( $246.62 \pm 15.0 \%$ of wild-type; $\mathrm{n}=3$ mice for each genotype; $\mathrm{m} \pm$ S.E.M.). (N) In wild-type mice, each AChR cluster is innervated (data not shown), whereas in $M u S K-H$ mice, $52.38 \pm 1.8 \%$ of AChR clusters are innervated ( $=3 M u S K-H$ mice). Scale bar $=20 \mu \mathrm{m}$ for $(A-F)$ and $10 \mu \mathrm{m}$ for $(\mathrm{G}, \mathrm{H})$ and $50 \mu \mathrm{m}$ for $(\mathrm{J}, \mathrm{K}, \mathrm{L})$. 

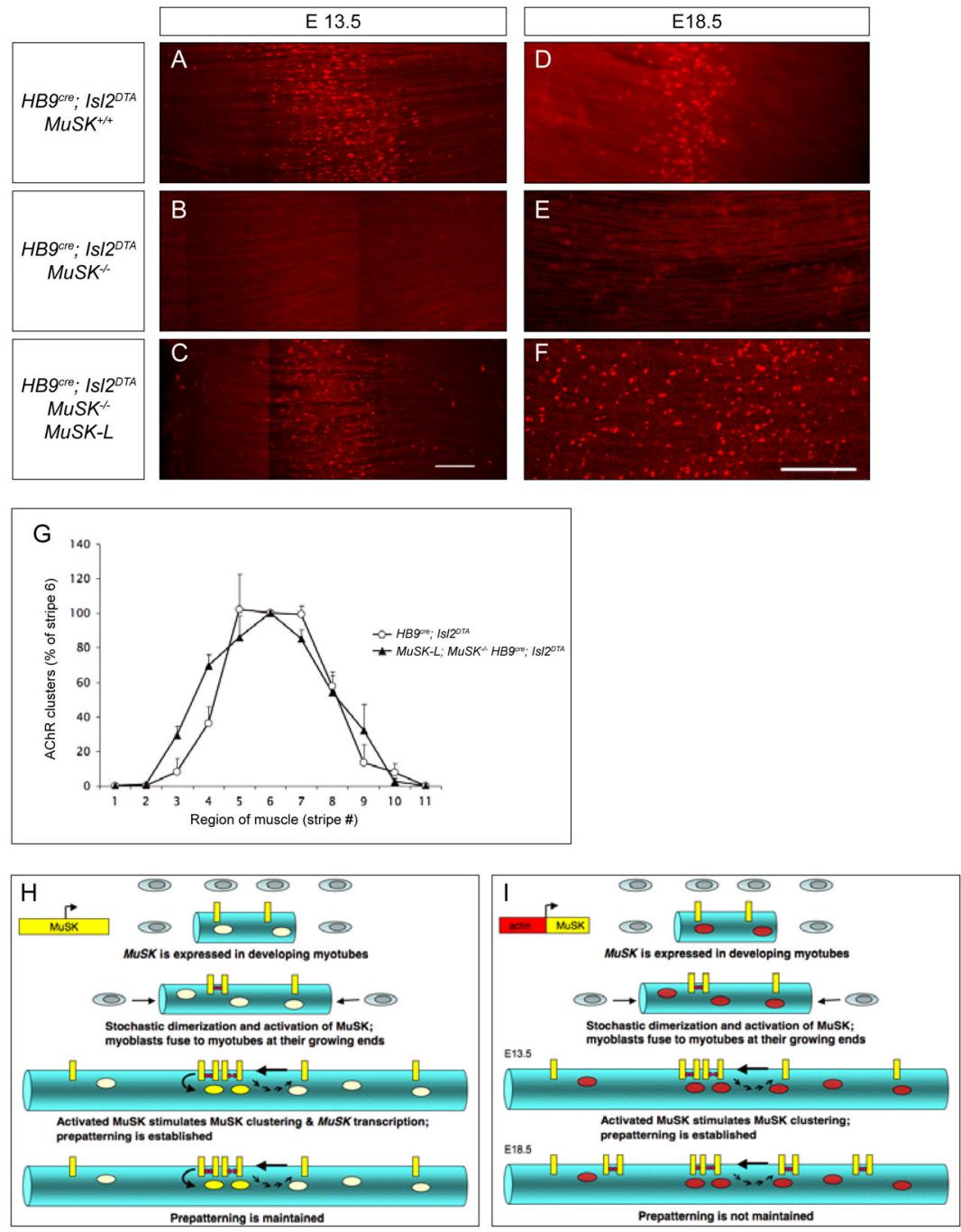

Figure 6. The actin::MuSK- $L$ transgene is sufficient to initiate but not maintain muscle prepatterning

Whole mounts of diaphragm muscles from E13.5 (A-C) or E18.5 (D-F) mice that lack (A, D) motor neurons $\left(H B 9^{c r e} ; I s l 2^{D T A}\right),(\mathrm{B}, \mathrm{E})$ motor neurons and endogenous $\mathrm{MuSK}$ (HB9 ${ }^{\text {cre }}$; $\left.I s l 2^{D T A} ; \mathrm{MuSK}^{-{ }^{-}}\right)$or $(\mathrm{C}, \mathrm{F})$ motor neurons and endogenous $M u S K$ but carry the $M u S K-L$ transgene $\left(H B 9^{\text {cre }}\right.$; Isl2 $\left.{ }^{D T A} ; \mathrm{MuSK}^{-/-} ; \mathrm{HSA}: \mathrm{MuSK}-\mathrm{L}\right)$ were stained with Alexa594- $\alpha$-BGT. AChRs are clustered in the central region of muscle from mice that lack motor axons (A, D) but not in muscle from mice that lack both motor axons and endogenous $\operatorname{MuSK}(\mathrm{B}, \mathrm{E})$. (C) Expression of the $M u S K-L$ transgene restores AChR clustering in the central region of muscle from E13.5 mice that lack motor neurons and endogenous $M u S K$, and the width of this zone is indistinguishable from control mice $(\mathrm{G})\left(\mathrm{n}=3 \mathrm{HB} 9^{c r e}\right.$; Isl $2^{D T A}$ and $2 \mathrm{HB} 9^{\text {cre }}$; $I s l 2^{D T A} ; \mathrm{MuSK}^{-/}$; HSA::MuSK-L mice). By E18.5, however, this restricted pattern of AChR expression is lost, since AChR clusters are found throughout the muscle of mice that carry the $M u S K-L$ transgene and lack motor neurons and endogenous $M u S K$. (H, I) A model for initiating and maintaining muscle prepatterning. $(\mathrm{H})$ Muscles grow in length by the fusion of myoblasts at the ends of developing myotubes. The $M u S K$ gene is activated early during myotube formation. Stochastic dimerization of MuSK protein in small myotubes leads to tyrosine phosphorylation and activation of MuSK. Activated MuSK stimulates two positive feedback loops, a post-translational feedback loop, which clusters MuSK protein, 
and a transcriptional feedback loop, which stimulates MuSK expression. Because MuSK activation occurs early during myotube formation and because muscles grow extensively from their ends, these feedback loops specialize the central region of the muscle and initiate and maintain muscle prepatterning. (I) The actin gene is likewise activated early during myotube formation, but the actin gene is uniformly expressed throughout muscle. Thus, in mice that lack endogenous $M u S K$ and carry the actin::MuSK-L transgene, expression of MuSK protein is initiated early, leading to stimulation of the post-translational feedback loop, but $M u S K$ RNA expression is not elevated in the central region of the muscle, since the actin promoter is not responsive to the transcriptional feedback loop. Thus, in these mice, muscle prepatterning is initiated but not maintained. Scale bar $=100 \mu \mathrm{m}$ for $(A-C)$ and 200 $\mu \mathrm{m}$ for (D-F). 


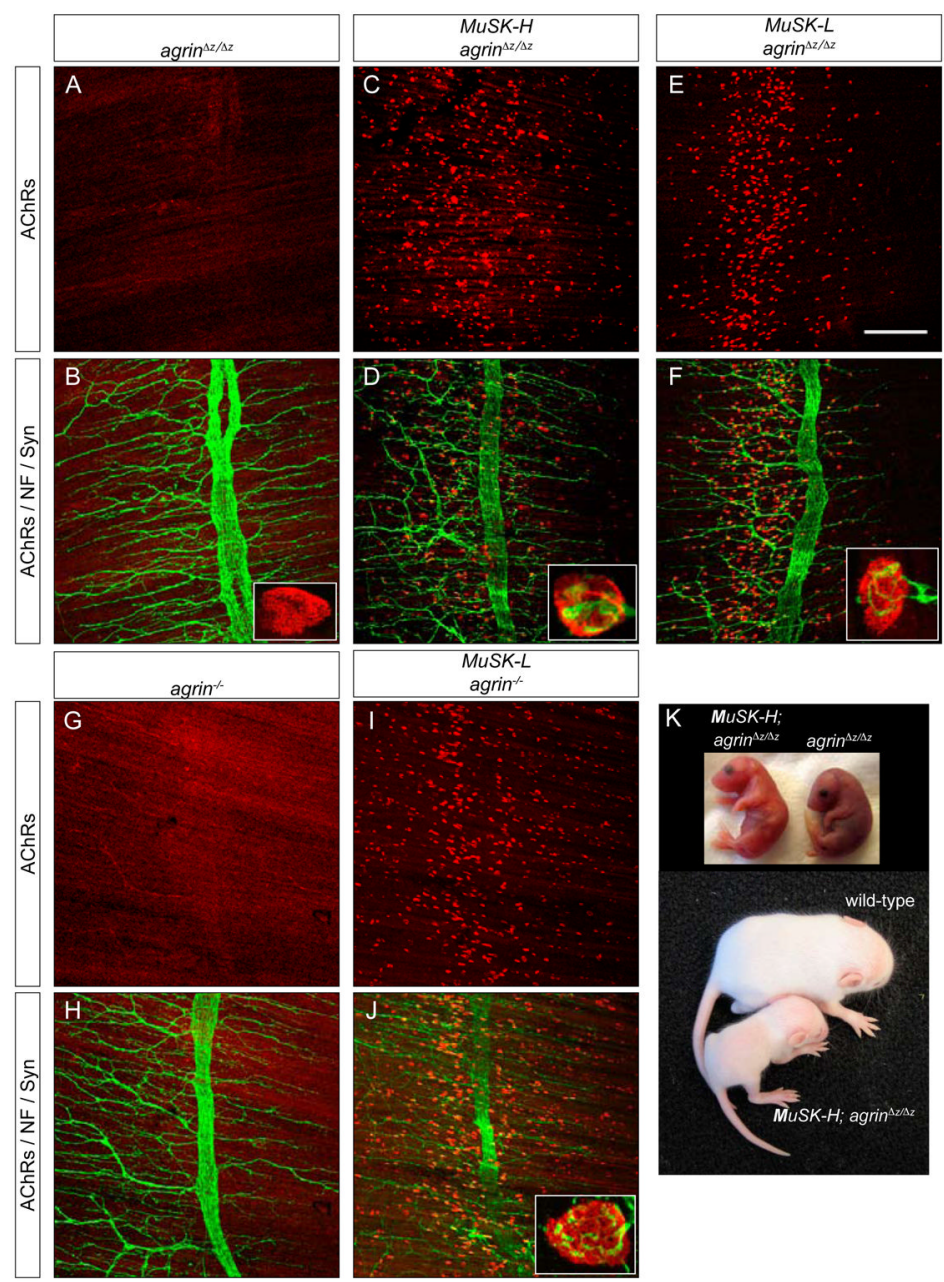

Figure 7. Ectopic MuSK promotes synapse formation and stabilization in the absence of Agrin In E18.5 mice lacking neural Agrin $\left(\right.$ agrin $\left.^{\Delta \mathrm{z} / \Delta \mathrm{z}}\right)(\mathrm{A}, \mathrm{B})$, or all forms of Agrin $\left(\right.$ agrin $\left.^{-1}\right)(\mathrm{G}$, $\mathrm{H})$, AChR clusters are sparse, small (Figure S5) and infrequently contacted by motor axons (B and Figure S5). In contrast, in E18.5 mice that lack neural Agrin and carry either the $M u S K-H(\mathrm{C}, \mathrm{D})$ or $M u S K-L$ transgene (E, F), larger AChR clusters are maintained in the muscle (Figure S5), and frequently contacted by motor axons that stop and differentiate as nerve terminals (D, F and Figure S5). Likewise, in mice that are null for Agrin and carry the $M u S K$ - $L$ transgene (I, J), AChR clusters are contacted by motor axons that differentiate as nerve terminals. Mice that lack neural Agrin die at birth, whereas mice that lack neural Agrin and carry either the $M u S K-L$ or $M u S K-H$ transgene survive postnatally for several weeks $(\mathrm{K})$, demonstrating that the $H S A:: M u S K$ transgenes can restore functional synapses. Mice that lack all isoforms of Agrin and carry either the $M u S K-L$ or $M u S K-H$ transgene also survive postnatally (data not shown). The restoration of functional synapses by either $M u S K$ transgene is also accompanied by a rescue in the level of $\mathrm{AChR}$ protein expression and in synapse-specific transcription (Figure S5). Scale bar $=200 \mu \mathrm{m}$. 